\title{
Development of TLC Chromatographic-Densitometric Procedure for Qualitative and Quantitative Analysis of Ceftobiprole
}

\author{
Żaneta Binert-Kusztal, Małgorzata Starek (1), Joanna Żandarek and Monika Dąbrowska *
}

Citation: Binert-Kusztal, Ż.; Starek, M.; Żandarek, J.; Dąbrowska, M. Development of TLC

Chromatographic-Densitometric Procedure for Qualitative and Quantitative Analysis of Ceftobiprole. Processes 2021, 9, 708. https://doi. org $/ 10.3390 / \operatorname{pr} 9040708$

Academic Editor: Ofelia Anjos

Received: 24 March 2021

Accepted: 14 April 2021

Published: 16 April 2021

Publisher's Note: MDPI stays neutral with regard to jurisdictional claims in published maps and institutional affiliations.

Copyright: (c) 2021 by the authors. Licensee MDPI, Basel, Switzerland. This article is an open access article distributed under the terms and conditions of the Creative Commons Attribution (CC BY) license (https:/ / creativecommons.org/licenses/by/ $4.0 /)$.
Department of Inorganic and Analytical Chemistry, Faculty of Pharmacy, Medical College, Jagiellonian University, 9 Medyczna St., 30-688 Kraków, Poland; zaneta.binert@uj.edu.pl (Ż.B.-K.); m.starek@uj.edu.pl (M.S.); joannazandarek@gmail.com (J.Ż.)

* Correspondence: monika.1.dabrowska@uj.edu.pl

Abstract: Currently, there is still a need for broad-spectrum antibiotics. The new cephalosporin antibiotics include, among others, ceftobiprole, a fifth-generation gram-positive cephalosporin, active against Staphylococcus aureus methicillin agonist (MRSA). The main focus of the work was to optimize the conditions of ceftobiprole qualitative determination and to validate the developed procedure according to ICH guidelines. As a result of the optimization process, HPTLC Cellulose chromatographic plates as a stationary phase and a mixture consisting of ethanol:2-propanol: glacial acetic acid: water $(4: 4: 1: 3, v / v / v / v)$ as a mobile phase were chosen. The densitometric detection was carried out at maximum absorbance of ceftobiprole $(\lambda=232 \mathrm{~nm})$. Next, the validation process of the developed procedure was carried out. The relative standard deviation (RSD) for precision was less than $1.65 \%$, which proves the high compatibility of the results, as well as the LOD $=0.0257 \mu \mathrm{g} / \mathrm{spot}$ and LOQ $=0.0779 \mu \mathrm{g} / \mathrm{spot}$ values, which also confirm the high sensitivity of the procedure. The usefulness of the developed method for the stability studies of ceftobiprole was analyzed. Study was carried out under stress conditions, i.e., acid and alkaline environments, exposure to radiation imitating sunlight and high temperature $\left(40-60^{\circ} \mathrm{C}\right)$. It was found that cefotbiprole is unstable in an alkaline environment and during exposure to UV-VIS radiation. Moreover, the lipophilicity parameter, as a main physicochemical property of the biologically active compound, was determined using experimental and computational methods.

Keywords: ceftobiprole; TLC method; validation of the method; stability testing; lipophilicity

\section{Introduction}

Cephalosporins, which belong to the group of semi-synthetic $\beta$-lactam antibiotics, have their origins as early as in the middle of the 20th century. The first research work on their use in the therapeutics was carried out at the turn of the 19th and 20th century. The discoverer of cephalosporins is considered to be the Italian scientist Giuseppe Brotzu (1895-1976), professor and microbiologist of the Medical Faculty in Cagliari (Sardinia). In 1945 the scientist became interested in people who swam in rivers polluted with faeces or consumed shellfish fished from them. These people did not get sick, while in other parts of Italy, there was a typhoid pandemic - at the time known as abdominal typhus. On this basis, Brotzu hypothesised that these sewage systems probably contain microorganisms that inhibit the growth of pathogenic intestinal bacteria-Salmonella typhi-that can prevent the spread of typhus [1]. In 1948, together with Howard Florey, they discovered that a strain of the fungus can produce seven antibiotics-five varieties of cephalosporin $\mathrm{P}, \mathrm{N}$ and $C$. The latter is considered to be the most important, as it is on its basis that all the cephalosporin antibiotics used today are created. Despite its considerable advantages, such as high resistance to staphylococcal penicillinase enzyme and hydrolysis in an acidic environment, like the rest of the natural penicillin, it has unfortunately not been used in 
the therapeutic field due to its low activity. For this reason, we are currently using its semi-synthetic derivatives obtained from 7-aminocephalosporic acid, which was formed as a product of the hydrolytic decomposition of cephalosporin $\mathrm{C}$. The basis for the structure of cephalosporins is the aforementioned 7-aminocephalosporic acid, which contains the characteristic $\Delta 2$-cephem system (Figure 1) [2].

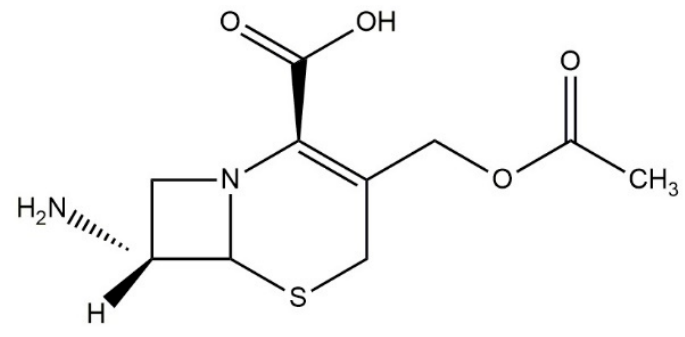

(a)

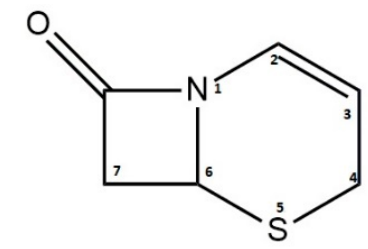

(b)

Figure 1. Chemical structure of 7-aminocephalosporic acid (a) and $\Delta 2$-cephem (b).

Cephalosporins belong to the well-tolerated group of antibiotics, which is extremely diverse and can be grouped into five classes in terms of their activity. The classification into a particular generation is based on the differences in action: bactericidal effect on Gram-negative bacteria (including Bacteroides and Gram-positive anaerobics), Proteus, Pseudomonas, reaching the cerebrospinal fluid and sensitivity to $\beta$-lactamases. It can be assumed that a lower generation has greater activity against Gram-positive bacteria, and a higher generation has greater activity against Gram-negative bacteria. There are some exceptions, such as cefepime, which is included in the fourth generation, and its activity against Gram-positive bacteria is comparable to that of the first generation, and against Gram-negative bacteria is equal to the third generation [3]. Currently, in a hospital and out-of-hospital treatment, there are infections caused by resistant strains of bacteria that are insensitive to methicillin. These are mainly Staphylococcus aureus, Streptococcus pneumoniae, Enterococcus spp. The use of similar chemotherapy regimens varies according to the type of hospital or out-of-hospital infection, as using the same regimens is not equally effective. Therefore, the need to look for new antibacterial compounds that will be able to overcome the existing resistance mechanisms is growing [4]. The new group of cephalosporin antibiotics includes the fifth generation. Unlike the fourth generation, these compounds have a broad spectrum of effect on Gram-positive bacteria and an extended spectrum of resistance to methicillin, i.e., MRSA and other resistant enterococci, mainly VRSA (S. aureus resistant to vancomycin) [5].

An example of generation $V$ cephalosporin is ceftaroline. It exhibits a wide spectrum of activity against Gram-positive and Gram-negative pathogens and most importantly it shows activity against VISA (S. aureus strain moderately resistant to vancomycin), hVISA (precursor of VISA), MRSA and VRSA. It has been proven effective against bacterial pathogens of the respiratory system, e.g., S. pneumoniae [6]. Ceftaroline is made from the prodrug ceftaroline fosamil. The indications for the use of this antibiotic are the complications caused by skin and soft tissues infections and community-acquired pneumonia [7]. The difference between ceftaroline and ceftobiprole is demonstrated in terms of their resistance to drug degrading enzymes, including $\beta$-lactamases. Ceftobiprole possesses high resistance, while ceftaroline has limited activity on Gram-negative bacteria, while the activity of ceftobiprole can be compared to fourth-generation antibiotics [8]. Besides ceftobiprole and ceftaroline, it is worth mentioning the latest fifth-generation semi-synthetic cephalosporin, ceftolozane. This drug was approved in 2014 by the FDA in combination with tazobactam, and is used in abdominal and urinary tract infections. In 2019, the combination of these drugs was authorised for hospital treatment of bacterial pneumonia, and is effective against the organisms causing these infections, such as Pseudomonas aeruginosa [9].

Ceftobiprole was first registered and authorised for marketing and hospital treatment in Canada in 2008 under the name Zevtera. The next countries to use this medicine 
were Switzerland and Ukraine. It is a pyrrolidine cephalosporin (Figure 2a), which was developed in cooperation between Johnson\&Johnson and Basilea Pharmaceutica. This compound is obtained by dissolving its prodrug in water, medocaryl ceftobiprole sodium salt (Figure 2b). Obtaining a derivative in the form of salt is necessary because ceftobiprole itself is insoluble in water. The given salt is obtained during a process consisting of three stages of synthesis. The metabolism of medocaryl ceftobiprole is dynamic. Salt is converted to active ceftobiprole, $\mathrm{CO}_{2}$ and diacetyl using enzymes called plasma esterases. A very small part of the prodrug is converted to an open ring form. This fact can be confirmed by a urine test, as it is mainly this way that the active drug is eliminated (up to 83\%) [4].<smiles>Nc1nc(/C(=N\O)C(=O)N[C@H]2C(=O)N3C(C(=O)O)=C(/C=C4\CCN([C@H]5CCNC5)C4=O)CS[C@H]23)ns1</smiles>

(a)<smiles>CC(=O)OC1=C(/C=C2\CCN([C@H]3CCN(C(=O)OCc4oc(=O)oc4C)C3)C2=O)CS[C@@H]2[C@H](NC(=O)/C(=N/O)c3nsc(N)n3)C(=O)N12</smiles>

(b)

Figure 2. Chemical structure of ceftobiprole (a) and medocaryl ceftobiprole sodium salt (b).

The mechanism of ceftobiprole's action is based on combining it with the penicillinbinding proteins (PBP), thus disturbing the synthesis of the cell wall (peptidoglycan). This leads to inhibition of cell growth and ultimately to the death of bacteria as a result of the osmotic activity or autolytic enzyme activity. It is related to specific proteins such as PBP2a in methicillin-resistant staphylococci, and PBP2b and PBP2x in $\beta$-lactam-resistant pneumococci [10-12]. The structures of cephalosporins of generations I-IV were not able to form a suitable bond with PBP2a. It was only the presence of a hydrophobic chain located at $\mathrm{C} 3$ carbon in the ceftobiprole that facilitated the binding and conformational changes in PBP2a, thanks to which it was possible to create an acyl-enzyme complex. The resistance of $S$. aureus and other staphylococci results from the acquisition and expression of mecA or mecC. These genes encode PBP2a, which is the protein that binds the penicillin. It shows a low level of affinity to $\beta$-lactams, thus preventing inhibition of cell wall synthesis [13].

Unlike ceftriaxone, ceftobiprole has a strong effect on penicillin-resistant $S$. pneumoniae (PRSP) via PBP2x protein. Thanks to interaction with PBP-type proteins, ceftobiprole also has high activity against other PBPS staphylococci (PBP1, PBP3, PBP4). An example of affinity for PBP2 and PBP3 is the binding of ceftobiprole in Escherichia coli $[14,15]$.

The indication for ceftobiprole application is adult pneumonia (CAP-Community Acquired Pneumonia) and hospital-acquired pneumonia (HAP-Hospital Acquired Pneumonia), but excluding ventilator treatment $[16,17]$. Ceftobiprole is a broad-spectrum antibiotic which can be used against several bacteria in monotherapy. In 2015, the FDA authorised it to treat diseases such as lung and skin infections. Its efficacy has been demonstrated in two-stage, third phase clinical trials with pneumonia patients. It was recommended to administer the drug every $8 \mathrm{~h}$ in a $2 \mathrm{~h}$ infusion in a dose of $500 \mathrm{mg}$ [18]. The microbiological diagnosis of bacterial pneumonia is usually difficult to establish, so action must be taken empirically. In general, S. pneumoniae is cited as the main cause of the disease in adults. To 
a lesser extent, infections are caused by P. aeruginosa and S. aureus (MRSA), which should definitely not be overlooked due to their resistance to antibiotic therapy. In hospital pneumonia, however, the most common cause of infection is Enterobacteriaceae bacteria, such as Klebsiella, Enterobacter, Serratia and only later Pseudomonas and Staphylococcus. Furthermore, these strains are resistant to many drugs, which underlines the seriousness of the situation in the case of the disease $[19,20]$.

Ceftobiprole can also be administered to patients during the treatment of complicated skin and soft tissue infections. Based on information contained in the pharmacovigilance study databases in Europe, S. aureus (37.5\%) was the main agent of skin and soft tissue infections, of which MRSA was $22.8 \%$. P. aeruginosa, E. coli and Enterococcus spp. were the lesser causes of the disease, so a broad-spectrum antibiotic becomes an obvious choice of empirical treatment [21]. The use of ceftobiprole is considered when the infections are severe and extensive, life-threatening, with a high content of methicillin-resistant staphylococci; patients hospitalized are elderly with coexisting diseases, mainly cirrhosis B and C and haemodialysis; the patient is undergoing immunosuppressive therapy; there are pretreated chronic ulcers with symptoms of infection; there are traumatic infections or surgical wounds [22]. The efficacy of ceftobiprole has also been analysed in the pharmacotherapy of diabetic foot infection. It was used in the moderate to the severe stage without bone involvement. The most common cause of this disease was, as above, in skin infections, S. aureus, while Gram-negative sticks such as P. aeruginosa were less frequent [23]. The in vitro ceftobiprole activity against anaerobic and aerobic isolates was investigated and compared with other antibiotics. It has been shown to have a wide range of effects on Gram-positive and Gram-negative aerobic and anaerobic bacteria. It is also more effective against Gram-positive aerobic bacteria than, e.g., cefepime, vancomycin, levofloxacin, ceftazidime or cefotaxime [24]. Moreover, in comparison to vancomycin (vancomycin with ceftazidime), it was found that the average treatment time was shorter -8.7 vs. 9.5 days. During the study, a faster response to treatment was obtained when ceftobiprole was applied to the patient [25]. Another indication for ceftobiprole application is infection from vascular catheters. Although treatment with ceftobiprole is beneficial, in the case of monotherapy, consideration should be given to whether it would not be better for the patient to use a combination of active glycopeptide against $P$. aeruginosa. This is since, in recent years, we have observed a significant increase in the number of cases caused by Gram-negative bacteria, mainly the previously mentioned P. aeruginosa and E. coli. The cause of this condition may be a solid organ transplant, previous use of $\beta$-lactams, long hospital stays or endured surgery $[26,27]$. The last indication for pharmacotherapy is fever in patients hospitalised without septic shock or severe immunosuppression. Once the fever has occurred and before treatment begins, it is necessary to collect bacterial culture samples because the main cause of the fever may be venous catheters, followed by infections depending on co-occurring diseases or local epidemiology [28].

Although ceftobiprole has no biological activity after oral administration, it shows similar pharmacokinetic properties on intravenous administration compared to other cephalosporins. The administered prodrug, ceftobiprole medocaril, is hydrolysed in the blood to active cephalosporin through esterases. As the drug is excreted only in the urine, the administered dose should be adjusted in persons with renal impairment or creatinine clearance $[29,30]$. It is easy to achieve optimal pharmacokinetic/pharmacodynamic $(\mathrm{PK} / \mathrm{PD})$ parameters in a 2-h infusion as the half-life period is more than $3 \mathrm{~h}[31,32]$. The recommended dose infusion is $500 \mathrm{mg}$ every $8 \mathrm{~h}$, but linear pharmacokinetics are observed for a dose range of $125-1000 \mathrm{mg}$, which is not dependent on the time of administration. The balance is obtained already on the first day. In patients with healthy kidneys, there is no drug accumulation when supplied every $8 \mathrm{~h}$. During the study, systemic exposure, the area under the curve (AUC) and maximum plasma concentration $\left(\mathrm{C}_{\max }\right)$ on day one and day five were similar (AUC $90 \pm 12.4 \mathrm{mg}$ h/ $\mathrm{L}$ and $102 \pm 11.9$; and $\mathrm{C}_{\max }$ was $29.2 \pm 5.52 \mathrm{mg} / \mathrm{L}$ and $33 \pm 4.83$ ). The systemic and renal clearance was also very similar. The half-life period $t_{1 / 2}$ on the first and fifth day was $3.3 \pm 0.3 \mathrm{~h}$ and $3.1 \pm 0.3 \mathrm{~h}$, respectively. These results are 
consistent with data characteristic for $\beta$-lactam antibiotics, especially cephalosporins [33]. The binding to plasma proteins is only $16 \%$, so penetration through tissues is facilitated. For example, during a single infusion of $500 \mathrm{mg}$, the penetration into striated muscles was $69 \%$ and into adipose tissue was $49 \%$ [34]. PK/PD profile was determined using the collected data, thus confirming that the possibility of reaching T > MIC (the time when the drug concentration is higher than Minimum Inhibitory Concentration (MIC)) about 30-40\% is more than $90 \%$ when MIC is equal to $2 \mathrm{mg} / \mathrm{L}$ in soft, adipose and bone tissues are taken into account [35]. For the safety of the antibiotic, an efficacy study was conducted with respect to the pharmacokinetic-dynamic index, in which serious side effects were excluded, and the most common side effect was a reversible change in taste [36,37].

According to the studies about using ceftobiprole in monotherapy, we can say that it is as effective as another antibiotic administered in the same indication. Furthermore, when compared to other cephalosporins, ceftobiprole shows a low risk of infection due to Clostridium difficile, and when compared to ceftaroline, there are no neutropenia-related adverse effects $[38,39]$. The efficacy of ceftobiprole against ceftazidime in the treatment of nosocomial pneumonia was also analyzed. Obtained results showed a slight percentage difference in the incidence of serious side effects, to the detriment of ceftobiprole, $3.9 \%$ vs. $3.1 \%$ [40]. During clinical trials, the effectiveness of ceftobiprole to vancomycin in the treatment of skin and soft tissue infections caused by Gram-positive microorganisms was compared, however no differences in tolerance were found [41]. Another study compared ceftobiprol with a combination of vancomycin and ceftazidime in the treatment of infections such as purulent diabetic foot and wounds (postoperative, traumatic and burn), finding no difference in treatment effectiveness and similar drug tolerance [42]. Despite good results and favourable safety and efficacy profiles, in 2010, the FDA and the EMA did not approve the use of ceftobiprole in tissue infection due to the absence or insufficient controls in about one-third of patients during clinical trials. The studies were found to be unreliable and were not conducted per good clinical practice [43]. For this reason, Basilea Pharmaceutica has launched Phase 3 studies to determine the effectiveness of treatment and the safety of ceftobiprole in relation to vancomycin with aztreonam.

Ceftobiprole, like other antibiotics, should be monitored for drug levels in the blood (Therapeutic Drug Monitoring Test (TDM)) to reduce hospitalization time and improve safety. Appropriate procedures for the determination methods should therefore be established. In the hospital use, one of this methods is high-performance liquid chromatography (HPLC) with spectrophotometric detection (DAD). The process involves the quantitative determination of the substance using calibration solutions. Chromatographic separation was carried out in mobile phase with a composition of acetonitrile-phosphate buffer, on biphenyl column in linear gradient mode. Ceftobiprole was monitored at wavelength $320 \mathrm{~nm}$. The method was validated and described by the guidelines of the European Medicines Agency demonstrating appropriate accuracy and precision. The other method for the determination of ceftobiprole is HPLC combined with tandem mass spectroscopy (MS/MS). Compared to the results obtained with the DAD detector, higher specificity and sensitivity are obtained. Future-oriented ceftobiprole studies are necessary to determine the exact therapeutic range with the required efficacy and safety [44].

The main subject of the presented investigations was to develop and optimize the conditions for the determination of ceftobiprole using thin-layer chromatography with densitometric detection. TLC with densitometric detection is a rapid and not complicated analytical technique for the separation, identification and quantification of medicinal substances. Its simplicity, low cost and the need for minimal cleaning of the sample allows for conducting various types of analyzes in different areas of science. Furthermore, TLC technique allows to perform several analyses simultaneously. The developed and validated chromatographic-densitometric method for the determination of ceftobiprole can be an alternative to the used HPLC method and can also be used in kinetic studies. To our knowledge, this is the first report in the scientific literature to carry out such studies. 


\section{Materials and Methods}

\subsection{Materials and Methods}

2.1.1. Chemicals and Apparatus

Methanol, chloroform, acetone, ethyl acetate, ammonia, glacial acetic acid were purchased from Merck (Darmstadt, Germany). Buffer solution ( $\mathrm{pH}$ 9.21) was purchased from Witko (Łódź, Poland). $\mathrm{HCl}, \mathrm{NaOH}$ and $\mathrm{H}_{2} \mathrm{O}_{2}$ solutions were purchased from POCh (Gliwice, Poland). All chemicals were an analytical grade.

Densitometer TLC Scanner 3 with Cat4 software (Muttenz, Camag, Switzerland), Linomat V (Muttenz, Camag, Switzerland), analytical balance XA 52/Y (Radom, Radwag, Poland), and Sunlight Simulator Suntest CPS + (Madrid, Spain) were used.

Chromatographic plates in size $20 \times 20 \mathrm{~cm}$, such as TLC Silica gel $60 \mathrm{~F}_{254}$ (No. 1.05554.0001), HPTLC Silica gel $60 \mathrm{~F}_{254}$ (No. 1.05548.0001), HPTLC Cellulose (No. 1.16092.0001) and TLC silica gel 60 RP-18 $\mathrm{F}_{254} \mathrm{~S}$ (No 1.05559) were purchased from Merck (Darmstadt, Germany).

\subsubsection{Standard Substance}

Ceftobiprole (BAL009141-000, No 08004R25F BAR004317 4.0) was obtained from Basilea Pharmaceutica (Basilea, Switzerland). The standard solutions have been prepared by weighting appropriate amounts of substance, and dissolving in certain volumes of water and methanol $(50: 50, v / v)$ mixture to obtain solutions of various concentrations: 0.001 , 0.01 and $0.1 \%$.

\subsubsection{Samples Solutions for Stability Study}

To perform the degradation tests of ceftobiprole, suitable solutions were prepared by weighing of the appropriate amounts of the substance to $5.0 \mathrm{~mL}$ glass vials, and dissolving in the following solvents: 0.1 M HCL, 0.001 M HCL, 0.1 M NaOH, 0.01 M NaOH, 0.001 M $\mathrm{NaOH}$, distilled water and buffer $\mathrm{pH} 9.21$.

\subsubsection{Chromatographic Conditions}

The ceftobiprole solutions in the form of $10 \mathrm{~mm}$ wide bands were applied to the chromatographic plates using a Linomat V sample applicator equipped with a $100 \mu \mathrm{L}$ syringe (Hamilton, Bondauz, Switzerland), with the speed in the range of 200-600 $\mu \mathrm{L} / \mathrm{s}$. The first application was $10 \mathrm{~mm}$ from the left edge of the plate and $10 \mathrm{~mm}$ from the bottom. In the case of large volumes of the solution, they were applied at time intervals. Plates were left to dry at room temperature and then developed in the vertical chromatographic chamber in size of $18 \times 16 \times 8 \mathrm{~cm}$ (Sigma-Aldrich, Laramie, WY, USA) in tested mobile phases. Once dry, visual detection under a UV lamp and densitometric scanning were performed.

\subsection{Validation of the Method}

Validation of the method was carried out taking into account a linearity and range of the developed method, limits of detection and quantification, and its precision and robustness, according to ICH guidelines [45].

\subsubsection{Linearity Range}

The linearity of an analytical method describes whether, within a given concentration range, we obtain measurement results that are directly proportional to the content of the substance in the sample. To determine linearity, a calibration curve was used, which is determined through several measurements at different concentration levels and can then be described by the mathematical equation: $y=a x+b$. The dependence of the substance concentration on the peak area is rectilinear only within a certain range. Regression parameters were determined, such as slope (a), intercept (b), the standard deviation of a slope $\left(S_{a}\right)$, the standard deviation of an intercept $\left(S_{b}\right)$, estimation error $\left(S_{e}\right)$ and correlation coefficient (r). Based on the obtained results the analysis of residuals have also been carried out. 


\subsubsection{Limit of Detection (LOD) and Limit of Quantification (LOQ)}

LOD is the lowest concentration or the lowest mass of an analyte that can be determined with appropriate accuracy in a sample using a particular analytical technique. It is related to the noise limit of the measurement process. It can be determined by one of the following methods: optical estimation, which consists in estimating the concentration using samples with a known analyte content and referring it to the test sample, determination by determining the ratio of the signal from the analysed analysis to noise (blank analysis) or by using a mathematical equation based on the parameters of the calibration curve:

$$
L O D=\frac{3.3 \times S b}{a}
$$

$L O Q$ is the smallest amount or concentration of a substance that we can determined by a chosen analytical method with sufficient precision and accuracy. This limit can be determined, like the $L O D$, by optical estimation or by applying a formula, using the parameters of the calibration curve:

$$
L O Q=\frac{10 \times S b}{a}
$$

where: $S b$ is the standard deviation of the intercept, $a$ is the slope of the calibration curve.

Both parameters are necessary when using the method for the determination of the drug substance content in pharmaceutical preparations.

\subsubsection{Precision}

Precision is a parameter that expresses the degree of agreement between the multiple results obtained with a specific analytical method. The increase in precision is observed while reducing the scatter of the results from the mean value. The parameter is influenced by systematic or random errors. The precision of analytical methods was assessed regarding repeatability (intra-day precision) and intermediate precision (inter-day precision). Precision is defined as checking to what extent the results of analyses carried out on the same sample will be compatible with each other. To determine the precision, at least 6 repetitions of the same concentration (mainly 100\%) or 3 different concentrations (in the range $50-150 \%$ of the nominal concentration) must be performed. The most common parameters of precision are standard deviation (S), relative standard deviation (RSD) or coefficient of variation (CV). The values of the last parameters should not exceed $3 \%$ for the main component of the sample.

\subsubsection{Robustness}

The robustness determines the ability of an analytical procedure to remain intact with minor, intended modifications of the parameters. Robustness provides information about the reliability of the analytical procedure in usual use.

The robustness of the proposed method was evaluated by the reliability of the analysis with respect variations in the experimental conditions, such as the sorbent type, e.g., HPTLC Cellulose, TLC Silica gel $60 \mathrm{~F}_{254}$, HPTLC Silica gel $60 \mathrm{~F}_{254}$ plates, the chamber size $(27 \times 27 \times 7 \mathrm{~cm}, 10 \times 11 \times 8 \mathrm{~cm})$, the chamber saturation time $( \pm 5 \mathrm{~min})$, the length of chromatographic plates development $( \pm 0.5 \mathrm{~cm})$, the small changes in volume of selected components in tested mobile phase $( \pm 0.1 \mathrm{~mL})$.

\subsection{Stability-Indicating Study}

\subsubsection{Environment}

Tests of ceftobiprole stability in acid and alkaline environments were conducted by placing previously prepared solutions in the heating block. The analysis was carried out for $24 \mathrm{~h}$ at $40{ }^{\circ} \mathrm{C}$ and $60^{\circ} \mathrm{C}$. Samples were taken at $1 \mathrm{~h}$ intervals and diluted with methanol $(1: 1, v / v)$. Then, the solutions were applied to the chromatographic plates in the volume of $10 \mu \mathrm{L}$ and further analysed under the developed method conditions. 


\subsubsection{UV-VIS Radiation}

To test the influence of solar radiation on the stability of ceftobiprole, analysis of aqueous antibiotic solutions were carried out in $10 \mathrm{~mL}$ quartz vessels with lids, which were and placed into the Suntest CPS+ solar radiation stimulating lamp equipped with a xenon lamp (it stimulates sunlight in the $300-800 \mathrm{~nm}$ wavelength range). The radiation intensity of $700 \mathrm{~W} / \mathrm{m}^{2}$ and the temperature of $35^{\circ} \mathrm{C}$ were kept constant at all times. The experiment was carried out for $24 \mathrm{~h}$, taking the individual solutions at 1-h intervals. Then the samples were diluted with methanol $(1: 1, v / v)$, applied on chromatographic plates in the volume of $10 \mu \mathrm{L}$, and subjected to analysis under the conditions of the developed method.

\subsection{Lipophilicity Study}

Designation of the lipophilicity parameters were carried out by the RP-TLC method. As mobile phases mixtures of proper amounts of water and methanol as an organic modifier in the range of 60 to $90 \%(v / v)$ in $5 \%$ steps were used. The study was performed on RP-18 silica gel $60 \mathrm{~F}_{254 \mathrm{~S}}$ plates $(10 \times 10 \mathrm{~cm})$. Solutions of the ceftobiprole in a volume of $10 \mu \mathrm{L}$ were applied using a Linomat $\mathrm{V}$ applicator, to the plates in the $10 \mathrm{~mm}$ bands, at intervals of $10 \mathrm{~mm}, 10 \mathrm{~mm}$ from the lower edge and sides of the plates. A chromatography chamber was saturated for $20 \mathrm{~min}$ with the appropriate mobile phase, and then the plates were developed to a high of $9.5 \mathrm{~cm}$. Next, the plates were dried at room temperature, and analysed at $\lambda$ $=232 \mathrm{~nm}$. Each study was repeated in triplicate and mean retardation factor $\left(R_{\mathrm{F}}\right)$ values were appointed, and then the $R_{M}$ parameters were calculated according to the rule $R_{M}$ $=\log \left(1 / R_{F}-1\right)$. Based on the obtained parameters, the linear correlations between $R_{M}$ values for each concentration of the methanol in mobile phases were established using the Soczewiński-Wachtmeister equation: $R_{M}=R_{M 0}+a C$, where $a$ is the slope, $C$ is the organic solvent concentration (\%) in the mobile phase, $\mathrm{R}_{\mathrm{M} 0}$ (the intercept) is the concentration of the organic modifier extrapolated to zero (value related to the molecular lipophilicity) [46].

\section{Results and Discussion}

Nowadays, antibiotics are one of the more dynamically developing groups of medicines. Currently, research is being conducted which focuses on the search for new antibiotics with a broad spectrum of effects. One of the representatives of the latest fifth generation cephalosporins is ceftobiprole, which shows good activity against both, Gram-positive and Gram-negative bacteria, and an additionally extended spectrum with the mentioned methicillin-resistant strains MRSA. Ceftobiprole was first registered and approved for marketing and hospital treatment in Canada in 2008 under the name Zevtera. Other countries using this medicine were Switzerland and Ukraine. The indication for administration of this antibiotic is complex infections of the skin and soft tissues and community-acquired pneumonia. The uniqueness of ceftobiprole is based on its broad spectrum of action, thanks to which it can be administered during treatment against one or more microorganisms in monotherapy.

The main objective of this study was to establish a method for the qualitative and quantitative analysis of ceftobiprole by thin-layer chromatography with densitometric detection. For this purpose, firstly, a number of parameters were optimized such as a kind of stationary and mobile phase, method of stationary phase activation, the development path, the rate of solution application on the plates, the time of saturation of the chromatographic chamber, the time from the application of solution on the plate to its placement into the chamber. To optimise the conditions different types of chromatographic plates were tested, such as TLC Silica gel $60 \mathrm{~F}_{254}$, HPTLC Silica gel $60 \mathrm{~F}_{254}$ and HPTLC Cellulose. During analyses carried out on TLC Silica gel $60 \mathrm{~F}_{254}$ and HPTLC Silicagel $60 \mathrm{~F}_{254}$ plates in mobile phases with variable solvent compositions, characterised by different eluotropic strengths, no spots that could originate from ceftobiprole were observed. Probably, this could be due to the active substance remaining at the start point or moving with the eluent front, i.e., too high an affinity of the tested substance to the mobile or stationary phase. While, on 
HPTLC Cellulose plates, a compact peak originating from ceftobiprole without additional background interferences was recorded by both visual and densitometric detection.

Also, it was assessed whether the activation of Cellulose HPTLC plates (incubation in a drying apparatus at $60{ }^{\circ} \mathrm{C}$ for $24 \mathrm{~h}$ ) affects improving the results of the analysis (compact spots with an appropriate $\mathrm{R}_{\mathrm{F}}$ values). No difference was observed in the obtained chromatographic image (peak shape and background level); the $R_{F}$ values obtained in 3 samples on each plate (activated and non-activated) was 0.32 . The development time (about $40 \mathrm{~min}$ ) also did not change.

In the study, mobile phases of the following composition were tested: chloroform: ethyl acetate: glacial acetic acid: water (4:4:4:1, v/v/v/v) and ethanol: 2-propanol: glacial acetic acid: water $(4: 4: 1: 3, v / v / v / v)$. It was found that a more favourable distribution (compact peak coming from the antibiotic, no blurring effect, an appropriate retardation factor value) was obtained using the second phase. The selected eluent was previously successfully used, for the quantification of cephalosporins 4th generation (cefepime). Both the type of stationary phase and the developing path $(9.5$ and $15 \mathrm{~cm})$ were tested. It was observed that the extension of the path did not affect the quality of the obtained chromatogram, the retardation factors for each of the tested paths were similar, 0.32 and 0.33 , respectively. The next step to optimise the assay was the speed of application of the ceftobiprole solution using the Linomat V. Two speeds were tested: 600 and $200 \mu \mathrm{L} / \mathrm{s}$, and finally the second one was chosen due to the width of the obtained spots. A too-fast application speed, especially for aqueous solutions, resulted in the formation of large fuzzy spots.

The influence of the time from the moment of applying the solution on the plate to the moment of putting the plate in the chromatographic chamber, on the quality of the obtained chromatogram was also checked. The following time intervals were tested: $0,5,10,15$, $20 \mathrm{~min}$. The results clearly demonstrated that the optimum time is $15 \mathrm{~min}$; an increase in the time does not affect the quality of the chromatogram. The time of the chromatographic chamber saturation with the eluent vapour was also optimised, and finally fixed at $15 \mathrm{~min}$.

After developing and drying at room temperature, chromatograms were detected under a UV lamp at wavelengths $254 \mathrm{~nm}$ and densitometrically. For the peaks recorded on the densitograms, absorption spectra in the range of $200-400 \mathrm{~nm}$ were recorded (Figure 3). Further analyses were carried out at a wavelength of $232 \mathrm{~nm}$, corresponding to the maximum absorption for ceftobiprole (Figure 4).

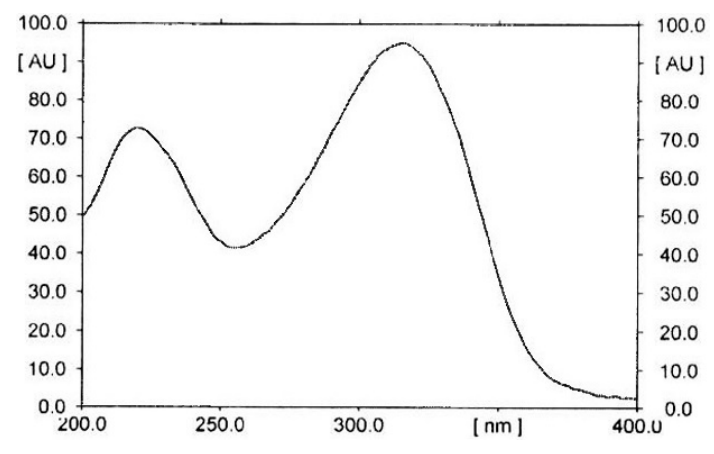

Figure 3. The absorption spectrum of ceftobiprole.

The next stage of the study was to carry out a validation process for the method of ceftobiprole determination according to ICH guidelines. Determination of linearity range was conducted by applying spots of $0.001 \%$ standard solution to HPTLC Cellulose chromatography plates in volumes ranging from 2 to $50 \mu \mathrm{L}$. For the recorded surface areas, a dependence curve was plotted, and regression parameters were calculated. Three repetitions were made for each determination, taking the mean value for the calculation. The value of the correlation coefficient ( $\mathrm{r}$ ) of 0.9978 indicates a very good correlation between the concentration and peak area in the investigated linearity range from 0.02 to $0.35 \mu \mathrm{g} / \mathrm{spot}$ (Figure 5a). The regression parameters were designated as follows: $y=12371.80 x+124.00$, 
$\mathrm{S}_{\mathrm{b}}=96.41, \mathrm{~S}_{\mathrm{a}}=444.89, \mathrm{~S}_{\mathrm{e}}=125.93$. The calculated LOD $(0.0257 \mu \mathrm{g} / \mathrm{spot})$ and LOQ $(0.0779 \mu \mathrm{g} / \mathrm{spot})$ values demonstrate the high sensitivity of the developed method.

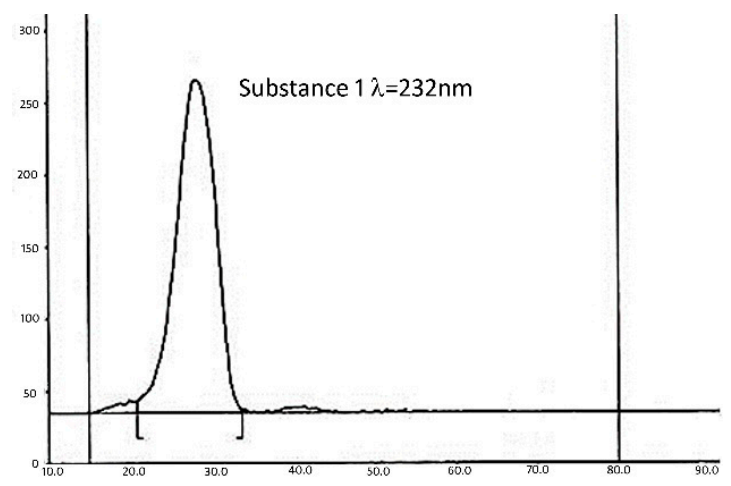

Figure 4. An example of densitogram recorded for ceftobiprole.

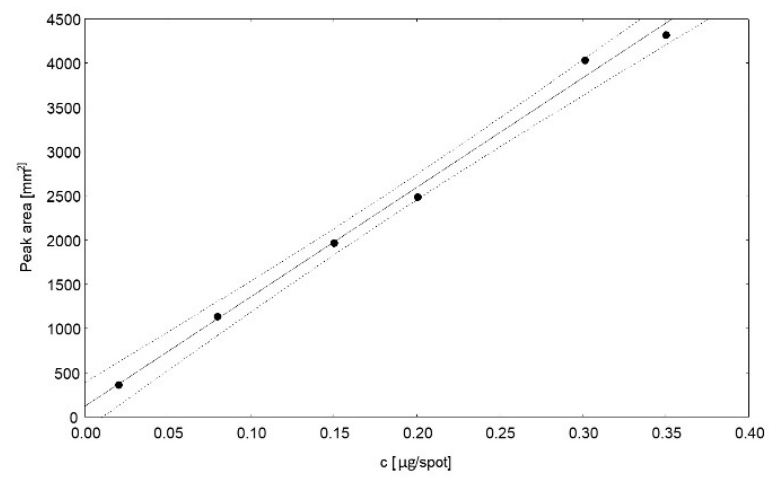

(a)

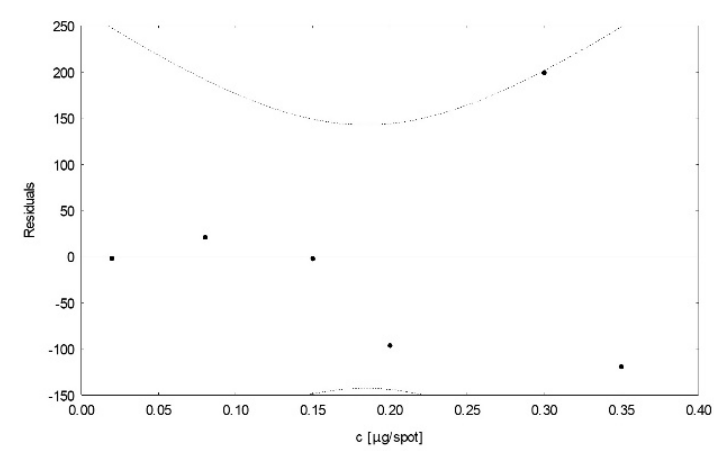

(b)

Figure 5. An example of linearity (a) and the plot of residuals (b) estimated for ceftobiprole.

Plotting the residuals enables to recognize problems with meagre or incorrect curve matching. Residuals analysis allows to check any regression assumptions and ensures that the obtained equation is correct. Thanks to this analysis we can easily and quickly detect outliers, which can distort the regression model. With this analysis, we can easily and quickly detect outliers that may distort the regression model. We can also detect inconsistencies between observed and predicted values. When the residuals are distributed randomly near zero, there is a good correlation between the obtained data and the regression model. The performed residual analysis confirmed the correctness of the obtained correlations, and Figure $5 \mathrm{~b}$ shows the residual scatter plot for the concentration values.

Cook's distance is a parameter related to the removed residuals. Its purpose is to assess the degree of change in the regression coefficients when a case is omitted from the 
coefficient calculations. For our data the average value of Cook's distance was 0.3331 . For the received data, we can infer that the residuals placed near zero, and are randomly scattered without any patterns. So, the hypothesis of linearity is correct, confirmed by there being no trend (in the relation of residuals with concentration), and for the examined points there are no significant deviations that could violate the obtained regression.

The precision of the method was assessed by analysing peak areas registered for ceftobiprole, within the same day for intra-day precision, and after a week for inter-day precision. Nine spots of $30 \mu \mathrm{L}$ each were applied to the chromatographic plate, and the analysis was performed in three replicates. The calculated low values of \%RSD (1.61 for intra-day and 1.65 for inter-day) indicated high precision of the described procedure for ceftobiprole solutions.

The robustness of the developed TLC method with densitometric detection was estimated on the basis of slight changes in the experimental conditions, e.g., sorbent nature, chromatographic chamber size, saturation chamber time, developing path, and volume of solvents in mobile phase. During the estimation, $R_{F}$ values and absorption spectra were registered, and not valid changes were observed in chromatographic conditions, which confirms that described method is robust.

Then, the usefulness of the developed chromatographic-densitometric method for the determination of ceftobiprole was verified by the analysis of drug stability under stress conditions. For all determinations, $10 \mu \mathrm{L}$ of a $0.01 \%$ ceftobiprole solution was applied onto the chromatography plates. Stability studies were conducted in solutions of $0.1 \mathrm{M} \mathrm{HCL}$, $0.001 \mathrm{M} \mathrm{HCL}, 0.1 \mathrm{M} \mathrm{NaOH}, 0.001 \mathrm{M} \mathrm{NaOH}$, distilled water and buffer pH 9.21. Samples were taken at hourly intervals (up to $5 \mathrm{~h}$, and after $24 \mathrm{~h}$ ) at 40 and $60^{\circ} \mathrm{C}$.

In all recorded densitograms, an additional peak with $\mathrm{R}_{\mathrm{F}}$ close to 0.64 appeared, next to the main peak of ceftobiprole. It probably comes from the degradation product of the active ingredient (Figure 6). The peaks were well separated and did not interfere with each other, which confirms the applicability of the developed method for the determination of ceftobiprole in the presence of additional compounds.

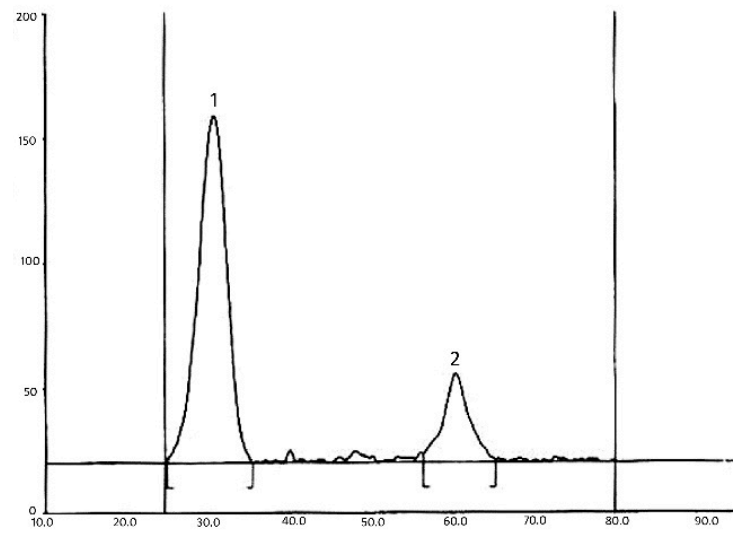

Figure 6. An example of densitogram recorded for ceftobiprole and its degradation product in acidic medium (1-ceftobiprole, 2-degradation product).

The obtained results indicate high stability of ceftobiprole in acidic and neutral medium. The concentration of the antibiotic, after $24 \mathrm{~h}$ of incubation in $0.1 \mathrm{M} \mathrm{HCl}$ decreased by $7.6 \%$, and in water by about $13 \%$ in comparison to the initial value. It was observed that recorded surface areas (concentration) significantly decreased with increasing $\mathrm{pH}$. In basic solutions, no peaks originating from the antibiotic were recorded after $24 \mathrm{~h}$, which indicates its complete degradation. In $0.001 \mathrm{M} \mathrm{NaOH}$, drug concentration successively decreased with incubation time, finally reaching $14.40 \%$ after $5 \mathrm{~h}$. The degradation process was found to be faster when the drug was incubated in basic medium compared to the buffer solution. A similar relationship was found when analysing changes in the concentration of the antibiotic at $60^{\circ} \mathrm{C}$. It was observed that after an hour of incubation in $0.1 \mathrm{M} \mathrm{NaOH}$, the ceftobiprole concentration decreased by $62.87 \%$, i.e., more than half of 
the initial concentration, while after $4 \mathrm{~h}$ the concentration was only $6.37 \%$. In the case of $0.01 \mathrm{M} \mathrm{NaOH}$ solutions, the areas of the recorded peaks decrease more slowly compared to more basic solutions; after $2 \mathrm{~h}$ of the experiment the drug concentration was $39.60 \%$ of the initial value, reaching $4.12 \%$ after $5 \mathrm{~h}$. The conducted experiments show that the stability of ceftobiprole decreases with increasing alkalinity of the solutions and temperature (Table 1).

Table 1. Concentration [\%] of ceftobiprole solutions under varying environmental and temperature conditions.

\begin{tabular}{|c|c|c|c|c|c|c|c|}
\hline \multicolumn{8}{|c|}{ Concentration [\%] } \\
\hline Time [h] & $0.1 \mathrm{M} \mathrm{HCl}$ & $0.01 \mathrm{M} \mathrm{HCl}$ & $\mathrm{H}_{2} \mathbf{O}$ & Buffer 9.21 & $0.001 \mathrm{M} \mathrm{NaOH}$ & $0.01 \mathrm{M} \mathrm{NaOH}$ & $0.1 \mathrm{M} \mathrm{NaOH}$ \\
\hline 0 & 100.00 & 100.00 & 100.00 & 100.00 & 100.00 & 100.00 & 100.00 \\
\hline \multicolumn{8}{|c|}{$40{ }^{\circ} \mathrm{C}$} \\
\hline 1 & 99.24 & 99.47 & 99.92 & 86.80 & 81.32 & 73.40 & 66.24 \\
\hline 2 & 98.02 & 98.96 & 97.60 & 79.06 & 55.97 & 48.51 & 37.60 \\
\hline 3 & 96.15 & 98.04 & 95.97 & 77.25 & 45.03 & 36.32 & 27.36 \\
\hline 4 & 95.98 & 96.66 & 93.06 & 74.50 & 18.54 & 17.95 & 17.37 \\
\hline 5 & 95.57 & 95.77 & 91.10 & 50.70 & 14.40 & 12.08 & 11.59 \\
\hline 24 & 92.40 & 93.37 & 86.73 & 20.81 & 0.00 & 0.00 & 0.00 \\
\hline \multicolumn{8}{|c|}{$60^{\circ} \mathrm{C}$} \\
\hline 1 & 98.13 & 97.44 & 96.98 & 85.22 & 73.21 & 61.02 & 37.13 \\
\hline 2 & 96.44 & 95.31 & 93.20 & 73.41 & 50.07 & 39.60 & 19.51 \\
\hline 3 & 95.90 & 93.52 & 90.57 & 70.03 & 39.20 & 23.99 & 14.05 \\
\hline 4 & 92.88 & 91.69 & 87.12 & 62.52 & 14.98 & 14.20 & 6.37 \\
\hline 5 & 92.02 & 88.85 & 86.49 & 47.33 & 3.38 & 4.12 & 0.00 \\
\hline 24 & 89.30 & 86.60 & 82.43 & 13.02 & 0.00 & 0.00 & 0.00 \\
\hline
\end{tabular}

Based on the calculated dependence of natural logarithms from ceftobiprole concentrations over time, the plotted curves of the dependence $\ln c=f(t)$ showed a rectilinear relationship. Therefore, it was found that the degradation of ceftobiprole in the studied conditions was consistent with the first order rates of kinetics reactions. Then, the values of the reaction rate constant $(\mathrm{k})$ and $\mathrm{t}_{0.5}$ and $\mathrm{t}_{0.1}$ times were calculated (Table 2).

The calculated values of kinetic parameters confirm the dependence that the degradation reaction rate constant increasing with the increase of $\mathrm{pH}$ and temperature (Table 3). The $\mathrm{k}$ values are higher in sodium hydroxide solutions and lower in acidic ones. The lowest values of the reaction rate constant were obtained for solutions prepared in 0.1 and $0.01 \mathrm{M}$ $\mathrm{HCl}\left(9.212 \mathrm{~h}^{-1}\right.$ at $\left.40^{\circ} \mathrm{C}\right)$, and the highest for $0.1 \mathrm{M} \mathrm{NaOH}$ at $60{ }^{\circ} \mathrm{C}\left(0.6886 \mathrm{~h}^{-1}\right)$.

Table 2. Statistical parameters describing the relationship $\ln c=f(t)$ for the ceftobiprole solutions.

\begin{tabular}{ccccccc}
\hline Parameter & $\mathbf{a}$ & Sa & $\mathbf{b}$ & $\mathbf{S b}$ & Se & $\mathbf{r}$ \\
\hline $0.1 \mathrm{M} \mathrm{HCl}$ & -0.0111 & 0.0012 & 4.6095 & 0.0038 & 0.0053 & 0.9755 \\
\hline $0.001 \mathrm{M} \mathrm{HCl}$ & -0.0097 & 0.0011 & 4.6110 & 0.0033 & 0.0045 & 0.9761 \\
\hline $\mathrm{H}_{2} \mathrm{O}$ & -0.0209 & 0.0014 & 4.6717 & 0.0042 & 0.0058 & 0.9911 \\
\hline Buffer 9.21 & -0.2414 & 0.0786 & 4.6786 & 0.2381 & 0.3290 & 0.8379 \\
\hline $0.001 \mathrm{M} \mathrm{NaOH}$ & -0.4100 & 0.0465 & 4.7633 & 0.1408 & 0.1945 & 0.9752 \\
\hline $0.01 \mathrm{M} \mathrm{NaOH}$ & -0.4320 & 0.0279 & 4.7067 & 0.0846 & 0.1168 & 0.9835 \\
\hline $0.1 \mathrm{M} \mathrm{NaOH}$ & -0.4325 & 0.0127 & 4.5881 & 0.03858 & 0.0533 & 0.9983 \\
\hline
\end{tabular}


Table 2. Cont.

\begin{tabular}{ccccccc}
\hline Parameter & $\mathbf{a}$ & Sa & $\mathbf{b}$ & Sb & Se & r \\
\hline $0.1 \mathrm{M} \mathrm{HCl}$ & -0.0206 & 0.0017 & 4.6114 & 0.0050 & 0.0069 & 0.9871 \\
\hline $0.001 \mathrm{M} \mathrm{HCl}$ & -0.0229 & 0.0009 & 4.6071 & 0.0027 & 0.0038 & 0.9969 \\
\hline $\mathrm{H}_{2} \mathrm{O}$ & -0.0963 & 0.0159 & 4.6690 & 0.0483 & 0.0667 & 0.9492 \\
\hline Buffer 9.21 & -0.1137 & 0.0186 & 4.5276 & 0.0563 & 0.0778 & 0.9504 \\
\hline $0.001 \mathrm{M} \mathrm{NaOH}$ & -0.6266 & 0.1163 & 4.9681 & 0.3522 & 0.4866 & 0.9374 \\
\hline $0.01 \mathrm{M} \mathrm{NaOH}$ & -0.5951 & 0.0639 & 4.7629 & 0.1934 & 0.2673 & 0.9777 \\
\hline $0.1 \mathrm{M} \mathrm{NaOH}$ & -0.6240 & 0.0881 & 4.4340 & 0.2158 & 0.2787 & 0.9714 \\
\hline
\end{tabular}

Table 3. Kinetics and pharmacokinetics parameters.

\begin{tabular}{|c|c|c|c|c|c|c|c|}
\hline Parameter & $0.1 \mathrm{M} \mathrm{HCl}$ & $0.01 \mathrm{M} \mathrm{HCl}$ & $\mathrm{H}_{2} \mathrm{O}$ & Buffer 9.21 & $0.001 \mathrm{M} \mathrm{NaOH}$ & $0.01 \mathrm{M} \mathrm{NaOH}$ & $0.1 \mathrm{M} \mathrm{NaOH}$ \\
\hline \multicolumn{8}{|c|}{$40^{\circ} \mathrm{C}$} \\
\hline $\mathrm{k}\left[\mathrm{h}^{-1}\right]$ & $9.212 \times 10^{-3}$ & $9.212 \times 10^{-3}$ & 0.0186 & 0.1336 & 0.3878 & 0.4238 & 0.4329 \\
\hline $\mathrm{t}_{0.5}[\mathrm{~h}]$ & 75.23 & 75.23 & 37.26 & 5.19 & 1.79 & 1.64 & 1.60 \\
\hline $\mathrm{t}_{0.1}[\mathrm{~h}]$ & 11.55 & 11.55 & 5.66 & 0.79 & 0.27 & 0.25 & 0.24 \\
\hline \multicolumn{8}{|c|}{$60^{\circ} \mathrm{C}$} \\
\hline $\mathrm{k}\left[\mathrm{h}^{-1}\right]$ & 0.0166 & 0.0234 & 0.0290 & 0.1496 & 0.6776 & 0.6380 & 0.6886 \\
\hline $\mathrm{t}_{0.5}[\mathrm{~h}]$ & 41.75 & 29.62 & 23.90 & 4.63 & 1.02 & 1.09 & 1.01 \\
\hline $\mathrm{t}_{0.1}[\mathrm{~h}]$ & 6.34 & 4.50 & 3.63 & 0.70 & 0.16 & 0.17 & 0.15 \\
\hline $\mathrm{Ea}[\mathrm{kJ} / \mathrm{moL}]$ & 25.78 & 40.80 & 19.44 & 4.95 & 24.42 & 17.91 & 20.32 \\
\hline
\end{tabular}

Parameters were calculated using the following formulae: $\mathrm{k}=2.303\left(\log \mathrm{c}_{1}-\log \mathrm{c}_{2}\right) /\left(\mathrm{t}_{2}-\mathrm{t}_{1}\right), \mathrm{t}_{0.5}=0.635 / \mathrm{k}, \mathrm{t}_{0.1}=0.1053 / \mathrm{k}$ and Ea $=-2.303$ $\mathrm{R}\left(\log \mathrm{k}_{1}-\log \mathrm{k}_{2}\right) /\left(1 / \mathrm{T}_{1}-1 / \mathrm{T}_{2}\right)$, where: $\mathrm{R}=8.315 \mathrm{~J} / \mathrm{mol} \mathrm{K}, \mathrm{k}_{2}>\mathrm{k}_{1}, \mathrm{~T}_{2}>\mathrm{T}_{1}$.

The calculated values of $t_{0.5}$ and $t_{0.1}$, as well as the activation energy (Ea), confirm the higher stability of ceftobiprole in an acidic environment compared to alkaline one.

The stability of ceftobiprole was also tested by exposing solutions to radiation simulating sunlight (Table 4). The tests were carried out on the Suntest CPS+ simulator equipped with a xenon lamp, which simulates natural sunlight in the wavelength range of $300-800 \mathrm{~nm}$.

Table 4. Changes in ceftobiprole concentrations [\%] during UV-VIS irradiation.

\begin{tabular}{|c|c|c|c|c|}
\hline Time [h] & $\begin{array}{c}\text { Radiation Dose } \\
{\left[\mathrm{kJ} / \mathrm{m}^{2}\right]}\end{array}$ & $\begin{array}{c}\text { Concentration } \\
{[\%]}\end{array}$ & Statistical Parameters & $\begin{array}{c}\text { Kinetic } \\
\text { Parameters }\end{array}$ \\
\hline 0 & 0 & 100.00 & \multirow{6}{*}{$\begin{array}{c}\mathrm{a}=-0.5134 ; \mathrm{S}_{\mathrm{a}}=0.0849 \\
\mathrm{~b}=4.9852 ; \mathrm{S}_{\mathrm{b}}=0.2571 \\
\mathrm{r}=0.9494 ; \mathrm{S}_{\mathrm{e}}=0.3554\end{array}$} & \multirow{6}{*}{$\begin{array}{c}\mathrm{k}=0.5163\left[\mathrm{~h}^{-1}\right] \\
\mathrm{t}_{0.5}=1.34[\mathrm{~h}] \\
\mathrm{t}_{0.1}=0.20[\mathrm{~h}]\end{array}$} \\
\hline 1 & 2483 & 91.98 & & \\
\hline 2 & 4936 & 76.11 & & \\
\hline 3 & 7243 & 38.84 & & \\
\hline 4 & 9716 & 21.60 & & \\
\hline 5 & 12046 & 7.57 & & \\
\hline
\end{tabular}

Analysing the obtained results, it can be concluded that the degradation process of ceftobiprole is also influenced by sunlight. By irradiating the aqueous solution of the antibiotic, it was found that after $3 \mathrm{~h}$ the concentration of ceftobiprole drops to $38.84 \%$, while after $24 \mathrm{~h}$ drug is completely degraded. The degradation process follows the kinetics 
of the first-order reaction, which is confirmed by the determined dependencies of $\ln (\mathrm{c})$ as a function of time. Similarly, calculated kinetic parameters confirm that, under the solar irradiation, the degradation takes place at the rate of $0.5163 \mathrm{~h}^{-1}\left(\mathrm{t}_{0.5}=1.34 \mathrm{~h}\right)$.

We have observed that the degradation process of ceftobiprole takes place in solutions, and is strongly dependent on the environment (acidic, alkaline, radiation), temperature and incubation time. On the basis of the obtained results, it can be concluded that ceftobiprole is more susceptible to degradation in an alkaline environment than in an acidic one.

By conducting research on the behaviour of ceftobiprole in various conditions, new information about this substance was obtained. One of the most important features of a drug substance is lipophilicity. Therefore, it was decided to determine the $\log \mathrm{P}$ values for the analysed antibiotic using the TLC technique and computational methods [47]. In recent years, the RP-TLC technique was often used to assess the lipophilicity of many different substances, and then the relationship of this feature with biological activity was assessed [48]. In the next stage of our research, lipophilicity was examined by RP-TLC method by determining appropriate $R_{F}$ values. Then the $R_{M}$ parameters were calculated, and analysed depending on the amount of organic modifier (methanol) in the used mobile phases. The obtained $R_{M}$ values increased linearly with the decrease in the amount of methanol in eluent (regression coefficients $r>0.97$; Figure 7). Then, based on the linear relationship between the $R_{M}$ values and the volume fraction of the organic modifier, the $\mathrm{R}_{\mathrm{M} 0}$ values corresponding to $100 \%$ of water were obtained by extrapolation. As can be seen, the experimentally obtained $\mathrm{R}_{\mathrm{M} 0}$ value for ceftobiprole (equivalent to the $\log \mathrm{P}_{\exp }$ value) is -1.4339 .

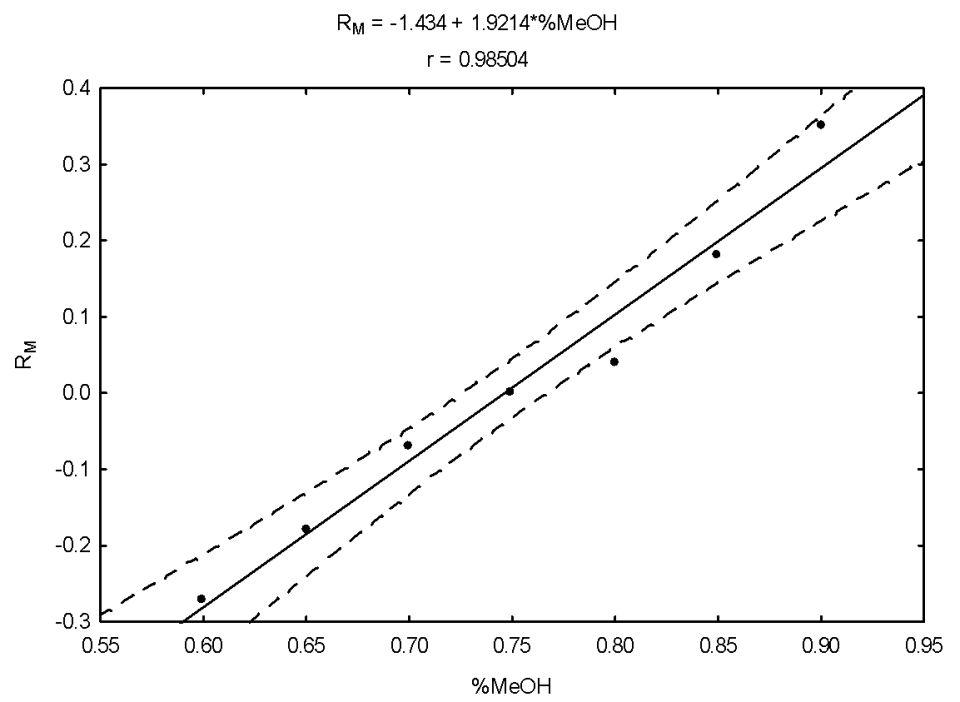

Figure 7. Dependence of $R_{M}$ value on the percentage of methanol organic modifier $(C)$, according to the equation $R_{M}=b+a \% C$. Statistical parameters $S a=0.1570, S b=0.1138, S e=0.039, F=163.3$.

Moreover, descriptors describing the lipophilicity of ceftobiprole were determined using the computational methods of the Virtual Computational Chemistry Laboratory, such as ALOGPs, AC_logP, ALOGP, MLOGP, XLOGP2, XLOGP3, ALOGPS and AClogS [49]. All the results reflecting the lipophilic properties of ceftobiprole, both determined experimentally (as parameter $\mathrm{R}_{\mathrm{M} 0} \approx \log \mathrm{P}_{\exp }$ ) and by calculation methods are presented in Figure 8.

When analyzing the received results, it can be noticed that $\log \mathrm{P}$ values determined (as $\mathrm{R}_{\mathrm{M} 0}$ and calculated using different algorithms) for ceftobiprole ranged from -3.53 for ALOGPS to 0.07 MLOGP.

Based on the calculated data (Figure 9) it can be concluded that the $\log \mathrm{P}_{\exp }$ lipophilicity parameter $\left(\mathrm{R}_{\mathrm{M} 0}\right)$ obtained in our study was the most similar to the computational data obtained by the ALOGP (based on electrotopological-state descriptors) and ALOGPs (based 
on the solubility descriptors) software, and both chromatographic and computational methods confirmed the hydrophilic character of ceftobiprole.

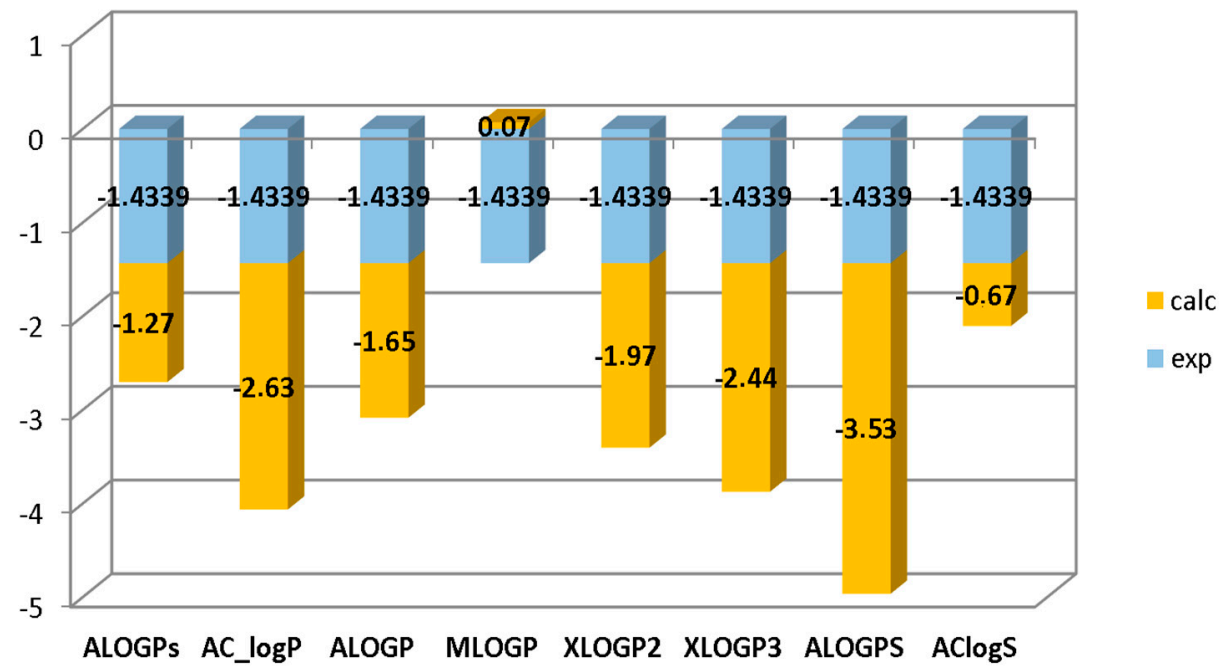

Figure 8. Determined $\mathrm{R}_{\mathrm{M} 0}$ and calculated partition coefficients for the ceftobiprole.

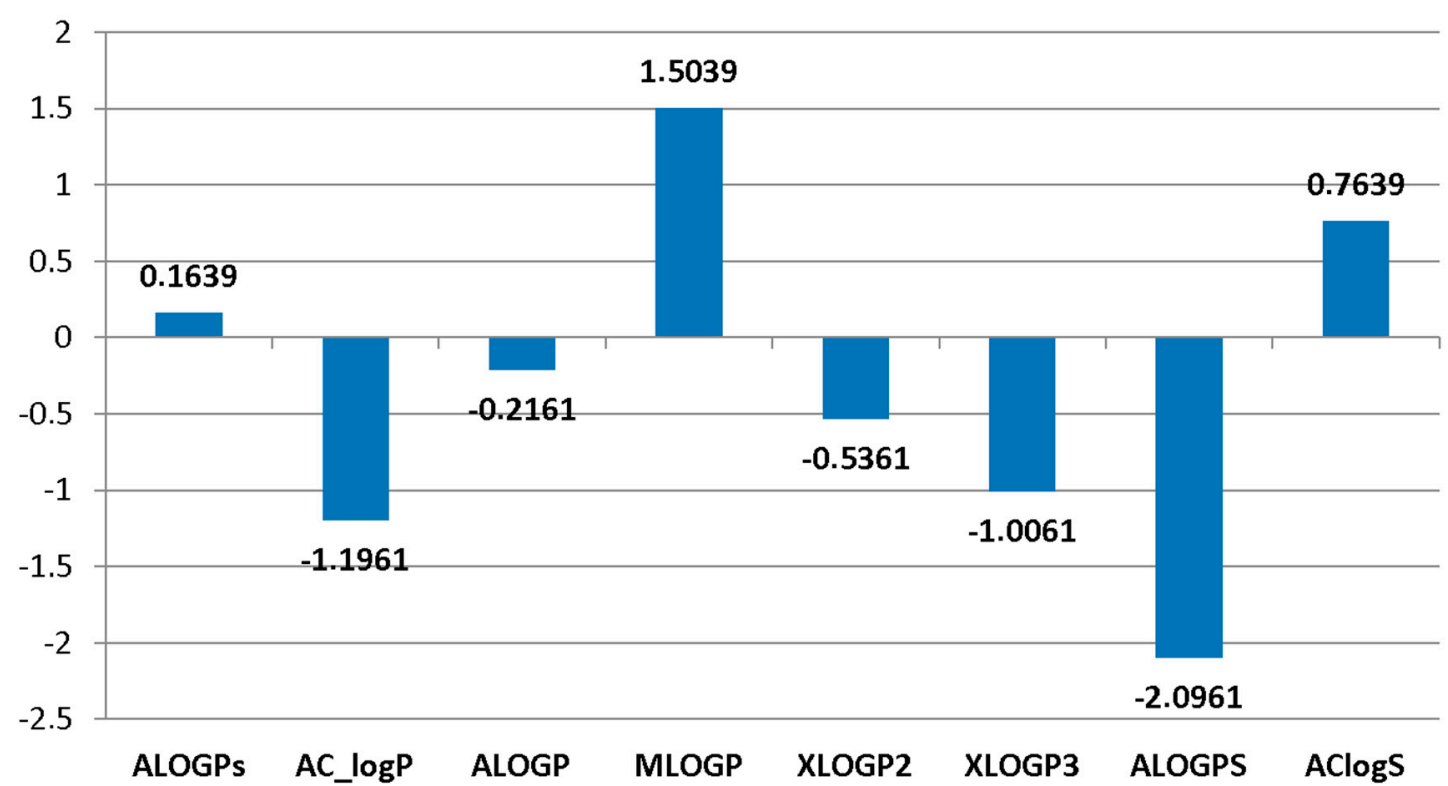

Figure 9. The comparison between measured $\mathrm{R}_{\mathrm{M} 0}$ and calculated $\log \mathrm{P}$ expressed as a difference (difference $=$ calculated minus measured).

In summary, the presented study discusses the optimization and validation process of a new chromatographic-densitometric method for the determination of ceftobiprole, a fifth generation cephalosporin. The developed chromatographic method allows for both qualitative and quantitative determinations, and is characterized by the simplicity of determinations with the possibility of performing several analyses at the same time. Due to the above features, it is relatively quick to determine not only the content of a given compound, e.g., in a pharmaceutical product, but also its purity. The obtained validation parameters allow to conclude that the method guarantees reliable results of active substance determination in the low concentration range. In addition, it provides high sensitivity and precision at a relatively low research cost compared to other analytical methods. Additionally, it has been proven that the presented procedure can be used for the analysis of an active substance in free form, as well as in the presence of potential degradation products. 


\section{Conclusions}

The conditions for the determination of the generation $\mathrm{V}$ cephalosporin, ceftobiprole, were developed and optimized. The validation of the developed chromatographicdensitometric method was carried out in accordance with the ICH guidelines. A high correlation of results was obtained $(r>0.99)$ in the tested linearity range. The precision values (below 1.65\%) confirm the consistency of the obtained results, and the LOD and LOQ values confirm the high sensitivity of the method. Stability studies of the drug under stress conditions were also performed by analysing the effects of $\mathrm{pH}$, temperature and irradiation. It was observed that ceftobiprole shows the lowest stability in alkaline environment, with increasing acidity of the environment, the stability of the antibiotic increases. While, under the solar irradiation, the tested drug is degraded over time, reaching a value of zero after $24 \mathrm{~h}$ of exposure. The developed analytical procedure for the determination of ceftobiprole may be an alternative to the currently-used HPLC method, and may also be used in kinetic studies of this drug.

Author Contributions: Conceptualization, M.D.; methodology, M.D. and Ż.B.-K.; formal analysis, Ż.B.-K. and J.Ż.; writing-original draft preparation, M.D. and Ż.B.-K.; writing-review and editing, M.S.; visualization, M.D. and M.S. All authors have read and agreed to the published version of the manuscript.

Funding: This research received no external funding.

Institutional Review Board Statement: Not applicable.

Informed Consent Statement: Not applicable.

Data Availability Statement: Data is contained within the article.

Acknowledgments: We thank Nathalie Dunkel, Clinical Study Manager from Basilea Pharmaceutica (Geneva, Switzerland) for sharing ceftobiprole standard for our research.

Conflicts of Interest: The authors declare no conflict of interest.

\section{References}

1. Wrzyszcz, E. Wybrane zagadnienia z historii chemioterapii. Arch. Hist. Fil. Med. 2015, 78, 16-25.

2. Kostowski, W.; Kubikowski, P. Farmakologia; PZWL: Warszawa, Poland, 1991; ISBN 83-200-15557-X.

3. Harrison, C.J.; Bratcher, D. Cephalosporins. Pediatr. Rev. 2008, 29, 264-273. [CrossRef]

4. Kurzynoga, D.; Głąbski, T.; Rusek, D. Ceftobiprol nowa cefalosporyna 5 generacji. Ter. Leki 2010, 66, 19-24.

5. Available online: http://www.uwm.edu.pl/antybiotykoopornoscwsrodowisku/antybiotyki-v-laktamowe (accessed on 10 November 2020).

6. Duplessis, C.; Cianflone, N.F.C. Ceftaroline: A new cephalosporin with activity against methicillin resistant Staphylococcus aureus (MRSA). Clin. Med. Rev. Ther. 2011, 3, 1-24.

7. Available online: https://www.mp.pl/pacjent/leki/subst.html?id=4987 (accessed on 10 November 2020).

8. Available online: https://pl.wikipedia.org/wiki/Cefalosporyny (accessed on 10 November 2020).

9. Available online: https://pubchem.ncbi.nlm.nih.gov/compound/Ceftolozane (accessed on 10 November 2020).

10. Morosini, M.I.; Aguilar, M.D.; Cantón, R. Mechanisms of action and antimicrobial activity of ceftobiprole. Rev. Esp. Quimiother. 2019, 32, 3-10.

11. Hebeisen, P.; Heinze-Krauss, I.; Angehr, P.; Hohl, P.; Page, M.G.; Then, R.L. In vitro and in vivo properties of Ro 63-9141, a novel broad-spectrum cephalosporin with activity against methicillin-resistant staphylococci. Antimicrob. Agents Chemother. 2001, 45, 825-836. [CrossRef] [PubMed]

12. Giacobbe, D.R.; De Rosa, F.G.; Del Bono, V.; Grossi, P.A.; Pea, F.; Petrosillo, N.; Rossolini, G.M.; Tascini, C.; Tumbarello, M.; Viale, P.; et al. Ceftobiprole: Drug evaluation and place in therapy 2019. Expert Rev. Anti. Infect. Ther. 2019, 17, 689-698. [CrossRef] [PubMed]

13. Lovering, A.L.; Gretes, M.C.; Safadi, S.S.; Danel, F.; Castro, L.; Page, M.G.P.; Strynadka, N.C.J. Structural insights into the anti-methicillin-resistant Staphylococcus aureus (MRSA) activity of ceftobiprole. J. Biol. Chem. 2012, 287, 1-6. [CrossRef]

14. Lakhundi, S.; Zhang, K. Methicillin resistant Staphylococcus aureus: Molecular characterization, evolution, and epidemiology. Clin. Microbiol. Rev. 2018, 31, 7-16. [CrossRef]

15. Lovering, A.L.; Barbour, M.C.A.; Schmidt, S.; Rand, K.H.; Derendorf, H. Ceftobiprole: A novel cephalosporin with activity against gram-positive and gram-negative pathogens, including methicillin-resistant Staphylococcus aureus (MRSA). Int. J. Antimicrob. Agents 2019, 34, 1-7. 
16. Charakterystyka Produktu Leczniczego Zevtera 500 mg. Available online: https://www.medicines.org.uk/emc/product/9164 / smpc (accessed on 10 November 2020).

17. Torres, A.; Mouton, J.W.; Pea, F. Pharmacokinetics and dosing of ceftobiprole medocaril for the treatment of hospital and community acquired pneumonia in different patient populations 2016. Clin. Pharmacokinet. 2016, 55, 1507-1520. [CrossRef] [PubMed]

18. Cillóniz, C.; Dominedò, C.; Garia-Vidal, C.; Torres, A. Ceftobiprole for the treatment of pneumonia. Rev. Esp. Quimioter. 2019, 32, 17-23.

19. Cillóniz, C.; Dominedò, C.; Nicolini, A.; Torres, A. PES Pathogens in severe community-acquired pneumonia. Microorganisms 2019, 7, 49. [CrossRef] [PubMed]

20. Koulenti, D.; Tsigou, E.; Rello, J. Nosocomial pneumonia in 27 ICUs in Europe: Perspectives from the EU-VAP/CAP study. Eur. J. Clin. Microbiol. Infect. Dis. 2016, 36, 1999-2006. [CrossRef] [PubMed]

21. Moet, G.J.; Jones, R.N.; Biedenbach, D.J.; Stilwell, M.G.; Fritsche, T.R. Contemporary causes of skin and soft tissue infections in North America, Latin America and Europe: A report from the sentry antimicrobial surveillance program (1998-2004). Diagn. Microbiol. Infect. Dis. 2007, 57, 7-13. [CrossRef]

22. Dryden, M.S. Complicated skin and soft tissue infection. J. Antimicrob. Chemother. 2010, 65, 35-44. [CrossRef]

23. Barberán, J.; Granizo, J.J.; Aguilar, L.; Alguacil, R.; Sainz, F.; Menéndez, M.A.; Gimenez, M.J.; Martinez, D.; Prieto, J. Predictive model of short-term amputation during hospitalization of patients due to acute diabetic foot infections. Enferm. Infecc. Microbiol. Clin. 2010, 28, 680-684. [CrossRef]

24. Goldstein, E.J.; Citron, D.M.; Merriam, C.V.; Warren, Y.A.; Tyrrel, K.L.; Fernandez, H.L. In vitro activity of ceftobiprole against aerobic and anaerobic strains isolated from diabetic foot infections. Antimicrob. Agents Chemother. 2006, 50, 3959-3962. [CrossRef]

25. Deresinski, S.D. The efficacy and safety of ceftobiprole in the treatment of complicated skin and skin structure infections: Evidence from 2 clinical trials. Diagn. Microbiol. Infect. Dis. 2008, 61, 103-109. [CrossRef]

26. Guembe, M.; Pérez-Granda, M.J.; Capdevila, J.; Barberán, J.; Pinilla, B.; Rabadán, M.P. Nationwide study on peripheral venous catheter associated bloodstream infections in internal medicine departments. J. Hosp. Infect. 2017, 97, 260-266. [CrossRef]

27. Ripa, M.; Morata, L.; Rodríguez-Núñez, O.; Cardozo, C.; Puerta-Alcalde, P.; Hernández-Meneses, M.; Ambrosioni, J.; Linares, L.; Bodro, M.; Valcárcel, A.; et al. Short term peripheral venous catheter related bloodstream infections: Evidence for increasing prevalence of gram negative microorganisms from a 25-year prospective observational study. Antimicrob. Agents Chemother. 2018, 62, 1-30. [CrossRef]

28. Available online: http://hws.vhebron.net/epine/Global/EPINE (accessed on 10 November 2020).

29. Backstrom, T.; Panagiotidis, G.; Beck, O.; Asker-Hagelberg, C.; Rashid, M.U.; Weintraub, A.; Nord, C.E. Effect of ceftobiprole on the normal human intestinal microflora. Int. J. Antimicrob. Agents 2010, 36, 537-541. [CrossRef]

30. Roos, B.; Schmitt-Hoffmann, A.; Schleimer, M.; Weidekamm, E.; Brown, T.; Heep, M. Safety and pharmacokinetics of BAL5788 in healthy subjects with normal or impaired renal function [abstract A-23]. In Proceedings of the 43rd Annual Interscience Conference on Antimicrobial Agents and Chemotherapy, Chicago, IL, USA, 14-17 September 2003; pp. 14-17.

31. Azanza-Perea, J.R.; de Rada, B.S.-D. Ceftobiprole pharmacokinetics and PK/PD profile. Rev. Esp. Quimioter. 2019, $32,11-16$.

32. Murthy, B.; Schmitt-Hoffmann, A. Pharmacokinetics and pharmacodynamics of ceftobiprole, an anti-MRSA cephalosporin with broad spectrum activity. Clin. Pharmacokinet. 2008, 47, 21-33. [CrossRef] [PubMed]

33. Murthy, B.; Skee, D.; Wexler, D.; Balis, D.; Chang, I.; Desai-Kreiger, D.; Noel, G. Pharmacokinetics of ceftobiprole following single and multiple intravenous infusions administered to healthy subjects [abstract P779]. Clin. Microbiol. Infect. 2007, 13, 194.

34. Barbour, A.; Schmidt, S.; Sabarinath, S.N.; Grant, M.; Seubert, C.; Murthy, B.S.; Derendorf, H. Soft tissue penetration of ceftobiprole in healthy volunteers determined by in vivo microdialysis. Antimicrob. Agents Chemother. 2009, 53, 2773-2776. [CrossRef]

35. Barbour, A.M.; Schmidt, S.; Zhuang, L.; Rand, K.; Derendorf, H. Application of pharmacokinetic/pharmacodynamic modelling and simulation for the prediction of target attainment of ceftobiprole against methicillin resistant Staphylococcus aureus using minimum inhibitory concentration and time-kill curve based approaches. Antimicrob. Agents Chemother. 2014, 43, 60-67. [CrossRef]

36. Schmitt-Hoffmann, A.; Roos, B.; Schleimer, M.; Sauer, J.; Man, A.; Nashed, N. Single-dose pharmacokinetics and safety of a novel broad spectrum cephalosporin (BAL5788) in healthy volunteers. Antimicrob. Agents Chemother. 2004, 48, 2570-2575. [CrossRef]

37. Awad, S.S.; Rodriguez, A.H.; Chuang, Y.C.; Marjanek, Z.; Pareigis, A.J.; Reis, G.; Scheeren, T.; Sánchez, A.; Zho, X.; Engelhardt, M.S. A phase 3 randomized double-blind comparison of ceftobiprole medocaril versus ceftazidime plus linezolid for the treatment of hospital-acquired pneumonia. Clin. Infect. Dis. 2014, 59, 51-61. [CrossRef] [PubMed]

38. Pfaller, M.A.; Flamm, R.K.; Duncan, L.R.; Streit, J.M.; Castanheira, M.; Sader, H.S. Antimicrobial activity of ceftobiprole and comparator agents when tested against contemporary Gram-positive and Gram-negative organisms collected from Europe. Diagn. Microbiol. Infect. Dis. 2018, 91, 77-84. [CrossRef] [PubMed]

39. Grau, S. Safety and tolerability of ceftobiprole. Rev. Esp. Quimioter. 2019, 32, 34-36.

40. Noel, G.J.; Strauss, R.S.; Amsler, K.; Heep, M.; Pypstra, R.; Solomkin, J.S. Results of a double blind randomized trial of ceftobiprole treatment of complicated skin and skin structure infections caused by gram-positive bacteria. Antimicrob. Agents Chemother. 2008, 52, 37-44. [CrossRef] [PubMed]

41. Noel, G.J.; Bush, K.; Bagchi, P.; Ianus, J.; Strauss, R.S. A randomized, double-blind trial comparing ceftobiprole, medocaril with vancomycin plus ceftazidime for the treatment of patients with complicated skin and skin-structure infections. AAC 2008, 46, 647-654. [CrossRef] [PubMed] 
42. Available online: https://www.clinicaltrialsarena.com/projects/ceftobiprole (accessed on 10 November 2020).

43. Available online: https:// clinicaltrials.gov/ct2/show /NCT03137173?term=Ceftobiprole\&draw=3 (accessed on 10 November 2020).

44. Lima, B.; Bodeau, S.; Quinton, M.-C.; Leven, C.; Lemaire-Hurtel, A.-M.; Bennisa, Y. Validation and application of an HPLC-DAD method for routine therapeutic drug monitoring of ceftobiprole. Antimicrob. Agents Chemother. 2019, 63, 1-6. [CrossRef] [PubMed]

45. ICH Guide Q2 (R1). Validation of Analytical Procedures Text and Methodology; International Conference on Harmonization: Geneva, Switzerland, 2005; Available online: https:/ / www.ich.org/page/quality-guidelines (accessed on 10 November 2020).

46. Soczewiński, E.; Wachtmeister, C.A. The relation between the composition of certain ternary two-phase solvent systems and RM values. J. Chromatogr. A 1962, 7, 311-320. [CrossRef]

47. Dabrowska, M.; Starek, M.; Skuciński, J. Lipophilicity study of some non-steroidal anti-inflammatory agents and cephalosporin antibiotics: A review. Talanta 2011, 86, 35-51. [CrossRef]

48. Dąbrowska, M.; Starek, M.; Komsta, Ł.; Szafrański, P.; Stasiewicz-Urban, A.; Opoka, W. Assessment of the chromatographic lipophilicity of eight cephalosporins on different stationary phases. Eur. J. Pharm. Sci. 2017, 101, 115-124. [CrossRef]

49. Virtual Computational Chemistry Laboratory. Available online: http:/ / www.vcclab.org (accessed on 10 November 2020). 